Cell Research, (2001); 11(1):44-54

\title{
Costimulation of resting B lymphocytes alters the IL-4-activated IRS2 signaling pathway in a STAT6 independent manner: impli- cations for cell survival and proliferation
}

\author{
ZAMORANO Jose*, Ann E KELLY, Jonathan AUSTRIAN, Helen Y WANG, Achsah D KEEGAN** \\ Department of Immunology, Jerome Holland Labs, American Red Cross, Rockville, MD, USA
}

\begin{abstract}
IL-4 is an important B cell survival and growth factor. IL-4 induced the tyrosine phosphorylation of IRS2 in resting B lymphocytes and in LPS- or CD40L-activated blasts. Phosphorylated IRS2 coprecipitated with the p85 subunit of PI 3' kinase in both resting and activated cells. By contrast, association of phosphorylated IRS2 with GRB2 was not detected in resting B cells after IL-4 treatment although both proteins were expressed. However, IL-4 induced association of IRS2 with GRB2 in B cell blasts. The pattern of IL-4induced recruitment of p85 and GRB2 to IRS2 observed in B cells derived from STAT6 null mice was identical to that observed for normal mice. While IL-4 alone does not induce activation of MEK, a MEK1 inhibitor suppressed the IL-4-induced proliferative response of LPS-activated B cell blasts. These results demonstrate that costimulation of splenic B cells alters IL-4-induced signal transduction independent of STAT6 leading to proliferation. Furthermore, proliferation induced by IL-4 in LPS-activated blasts is dependent upon the MAP kinase pathway.
\end{abstract}

Key words: B lymphocytes, IL-4, survival, proliferation.

\section{INTRODUCTION}

The inappropriate enhancement of lymphocyte survival due to a block in programmed cell death and/or an enhancement of entry into the cell cycle can contribute to the abnormal expansion of clones resulting in tumorigenesis or the breakdown of peripheral self-tolerance[1],[2]. Proper lymphocyte homeostasis is critical for normal immune function and is maintained by a complex series of cellular interactions and the action of secreted cytokines.

* Current address: Unidad de Investigacion, Hospital San Pedro de Alcantala, Avda Millan Astray, 10003 Caceres

* * Address correspondance to: Dr.Achsah D. Keegan, Immunology Department, Jerome Holland Laboratories, American Red Cross, 15601 Crabbs Branch Way, Rockville, MD 20855, (301) 517-0326, Fax: (301) 517-0344, E-mail: keegana@usa.redcross.org Abbreviations: IL-4, interleukin-4; JAK, Janus kinase; STAT6, signal transducer and activator of transcription 6; IRS, insulin receptor substrate; GRB2, growth-factor receptor bound protein 2; MAPK, mitogen activated protein kinase; ERK, extracellular signal regulated kinase; MEK, mitogen protein kinase. Received Nov8-2000. Revised Dec-26-2000. Accepted Jan-9-2001.
Interleukin-4 (IL-4), a cytokine produced by T cells, mast cells, and basophils, has profound effects on the growth and differentiation of $\mathrm{B}$ and $\mathrm{T}$ lymphocytes[3]. As an important growth and survival factor for normal B cells, IL-4 maintains the viability of small, resting $B$ cells, but is unable to induce cellular proliferation without a co-stimulatory agent such as bacterial lipopolysaccharide (LPS) or CD40 stimulation[4-6]. Additionally, IL-4 has been shown to reverse the effects of certain stimuli that inhibit $B$ cell activation, such as tolerogenic doses of anti-IgM[7],[8], the cross-linking of surface IgM and Fc receptors[9], and the susceptibility of CD40L-activated B cells to FasL-mediated death[10]. Although major advances have been made in understanding the structure of the IL-4 receptor complex and the biochemical signaling pathways that are activated by the binding of IL-4 to its receptor[11], most of these pathways have been analyzed in long-term factor-dependent lines. 
The mechanism by which IL-4 signals in normal lymphocytes is still unclear.

IL-4 binds to a cell surface receptor complex consisting of the IL-4 binding chain (IL-4R $\alpha$ ) and either the common $\gamma$ chain $(\gamma \mathrm{c})$ or a component of the IL-13 receptor (IL-13R $\alpha$ )[12]. The IL-4Ra associates with the Janus family kinase JAK1 and the $\gamma$ c associates with JAK3[13-15]. Occupancy of the IL-4 receptor induces tyrosine phosphorylation of the IL- $4 \mathrm{R} \gamma$ itself and of a 170-180 $\mathrm{kDa}$ protein, operationally defined as IL-4-induced phosphorylated substrate, 4PS, in many IL-4-responsive cell types[16]. 4PS was termed IRS2 due to its homology to the insulin receptor substrate-1 (IRS1), a substrate of the insulin receptor kinase[17,18]; both substrates act as important signaling molecules for the IL-4, insulin and insulin-like growth factor-I (IGF-I) receptors[18].

IRS1 and IRS2 are not highly homologous at the DNA level, but they contain localized regions of high homology at the amino acid level[18]. Both contain numerous potential tyrosine phosphorylation sites and numerous potential serine/threonine phosphorylation sites. Tyrosine phosphorylation of sites within both IRS1 and IRS2 allows their high affinity association with cellular proteins that contain $\mathrm{SH} 2$ domains including the p85 regulatory subunit of PI 3' kinase (PI-3K), growth-factor receptor-bound protein 2 (GRB2), and the src-homology protein tyrosine phosphatase 2 (SHP2), as well as other signaling molecules. The precise role of these recruited signaling molecules in regulating responses to IL-4 is not well understood.

Previous studies, focusing on the IL-3-dependent myeloid progenitor cell type $32 \mathrm{D}$, support a role for IRS family members in signaling the IL-4induced proliferation and prevention of apoptosis. $32 \mathrm{D}$ cells expressing the cDNA encoding IRS1 or IRS2 (32D-IRS) are able to mount a mitogenic response to IL-4[18,19], while 32D cells lacking IRS expression are not. In these transfected cells, IL-4 readily induces the tyrosine phosphorylation of IRS and its association with p85 and GRB2; a proliferative response to IL-4 has been associated with IRS docking to GRB2[20]. The adaptor GRB2 binds to the protein encoded by son-of-sevenless, SOS, the nucleotide exchange factor that regulates the Ras/Raf/mitogen activated protein kinase (MAPK) pathway. However, the ability of IL-4 to activate this pathway is controversial [reviewed in 11]. A number of studies have found that IL-4 does not stimulate the tyrosine phosphorylation of SHC, the activation of ras, the phosphorylation of raf, or the tyrosine phosphorylation of extracellular signal regulated kinase (ERK)[11,21]. There are some studies, however, that show several cell lines do respond to IL-4 with weak tyrosine phosphorylation of SHC and ERK[11,21].

Overexpression of IRS1 has been shown to protect $32 \mathrm{D}$ cells from death induced by IL-3 deprivation[22]. The IRS1-dependent prevention of apoptosis was associated with the activation of PI 3' kinase since wortmannin and LY294002, two inhibitors of PI 3 ' kinase[23,24], partially inhibited the protection from apoptosis mediated by IL-4. In addition, it has been shown that treatment of small, resting B cells with IL-4 results in the potent tyrosine phosphorylation of a $180 \mathrm{kDa}$ protein that is precipitated by IRS2-specific antisera, but not by IRS1 specific antisera[22],[25]. Furthermore, wortmannin and LY294002 blocked the protection from spontaneous apoptosis by IL-4[22] suggesting the IRS2/PI 3' -kinase pathway is important for the IL-4-induced protection of normal B cells from apoptosis. Indeed, resting B cells purified from mice lacking expression of the p85a subunit of PI 3 ' kinase in the lymphocyte compartment were not protected from apoptosis by IL-4[26].

The role of STAT6 in the regulation of B-cell proliferation and protection from apoptosis in response to IL-4 is unclear. Several lines of evidence indicate that the activation of two major biochemical pathways, IRS and STAT6, by IL-4 are independent of each other at the induction stage of the signal transmission. In 32D cells lacking IRS1 or IRS2 expression, IL-4-treatment is able to activate STAT6 DNA-binding activity[27]. On the other hand, IL-4 is able to stimulate the tyrosine phosphorylation of IRS2 in lymphocytes derived from mice deficient in STAT6 expression as well as in lymphocytes derived from normal mice[28]. Several reports suggests that STAT6 may not contribute to the IL-4-induced survival of T cells[29,30]. While the early biochemical pathways activated by IL-4 are distinct, new evidence suggests that they may overlap further downstream leading to coop- 
eration in a final biologic outcome. Three independent laboratories showed that STAT6 null mice have a modest to substantial diminution in IL-4induced co-stimulation of B and T cell growth[3133 ] in response to antigen receptor cross-linkage suggesting that STAT6 is involved in regulating the proliferative response.

While there are many analyses of IL- 4 signal transduction in long-term cell lines and a few using primay $\mathrm{T}$ cells [11], there is only limited information on the molecular mechanism of IL-4 signaling in normal B lymphocytes. To characterize the regulation of normal B cell survival and proliferation in response to IL-4, we analyzed the signaling pathways involved in the IL-4-mediated proliferation and protection from apoptosis in normal and STAT6 null B lymphocytes. We found that IL-4 protects both resting and activated B cells from apoptosis and that this activity is correlated with PI 3' kinase recruitment to IRS2 in both control and STAT6 null B cells. In addition, we found that costimulation of splenic B cells with LPS or CD40L can alter IL-4-induced signal transduction, independent of STAT6 expression, such that IRS2 will coprecipitate with the SOS-binding adaptor GRB2. Furthermore, we provide evidence that the proliferation induced by IL-4 in LPS blasts is dependent upon the PI 3' kinase pathway and the MAP kinase pathway.

\section{MATERIALS AND METHODS}

\section{Cells and reagents}

The B cell lymphoma M12.4.1 (obtained from Dr. Richard Asofsky, NIAID, NIH) was maintained in RPMI-1640 culture medium (Biowhittaker, Gaithersberg, MD) supplemented with $10 \% \mathrm{FBS}, 100 \mathrm{U} / \mathrm{ml}$ penicillin, $100 \mu \mathrm{g} / \mathrm{ml}$ streptomycin, $2 \mathrm{mM}$ glutamine, and $1 \times 10^{-7} \mathrm{M}$ 2-mercaptoethanol. B6D2/F1 mice were purchased from Jackson Laboratories (Bar Harbor, ME). Mice lacking STAT-6 expression[33], generated by the laboratory of Dr. James Ihle, St. Jude Children' s Research Hospital, were generously provided by Dr. William E. Paul and Ms. Cyndy Watson. Mouse splenic cells were obtained by mechanical disruption following incubation in lysis buffer $(0.15 \mathrm{M} \mathrm{NH} 4 \mathrm{Cl}, 1.0$ mM KHCO3, 0.1 mM EDTA, pH 7.2) for 5 min to remove red cells. Where indicated small, resting splenic murine B cells were purified by Percoll gradient fractionation after treatment of total spleen cells with anti-Thy and complement. Purified B cells from the 70-66\% Percoll layer were incubated with media alone or in the presence of $20 \mu \mathrm{g} / \mathrm{ml}$ lipopolysaccharide (Sigma Chemical C0., St. Louis, MO) or with $3 \mu \mathrm{g} / \mathrm{ml}$ of a membrane preparation containing recombinant CD40L (a generous gift of Dr. Marilyn Kehry, Boehringer Ingelheim) for $48 \mathrm{~h}$ at $37^{\circ} \mathrm{C}$. Recombinant mIL-4 was obtained from R and D Systems (Minneapolis, MN). Wortmannin was purchased from Sigma (St Louis, MO). LY294002, PD98059, and SB203580 were obtained from Calbiochem.

\section{Apoptosis assay}

Percentage of apoptotic cells was determined by analyzing the nuclear DNA content by flow cytometry[34]. Splenic cells were stained with FITC-conjugated anti-B220 monoclonal antibody (Pharmigen, San Diego, California). After washing in PBS, the cells were incubated overnight in $75 \%$ ethanol at $4^{\circ} \mathrm{C}$. The cells were then washed with PBS and incubated for $30 \mathrm{~min}$ in PBS containing $50 \mu \mathrm{g} / \mathrm{ml}$ propidium iodide and $50 \mu \mathrm{g} / \mathrm{ml} \mathrm{RNase}$ (Sigma Chemical Co, St. Louis, MO.). DNA content of B220+ cells was analyzed in a FACScan cytometer (FACScan, Becton Dickinson). The apoptotic cells were defined as those with less than a $2 \mathrm{~N}$ DNA content. Where indicated cell viability was determined by trypan blue dye exclusion.

\section{Immunoprecipitation and immunoblotting}

Analysis of IRS tyrosine phosphorylation and coprecipitation with signaling molecules was performed as previously described [35]. Briefly, cells were deprived of serum in RPMI for $2 \mathrm{~h}$ at $37^{\circ} \mathrm{C}$. After washing, $10^{7}$ cells were resuspended in RPMI and incubated in the presence or absence of murine IL-4 (10 ng/ml) for $10 \mathrm{~min}$ at room temperature. The reaction was terminated by 10 -fold dilution in ice-cold PBS. Cell pellets were lysed in HEPES lysis buffer (50 mM HEPES, $150 \mathrm{mM} \mathrm{NaCl}, 0.5 \%$ NP-40, $1 \mathrm{mM}$ $\mathrm{Na}_{3} \mathrm{VO}_{4}, 50 \mathrm{mM} \mathrm{NaF}, 10 \mathrm{mM}$ pyrophosphate, $1 \mathrm{mM}$ PMSF, and protease inhibitor cocktail) and clarified. Protein determination was made using the BioRad kit according to the manufacturer. The soluble fraction was immunoprecipitated with a polyclonal rabbit anti-IRS2 (a generous gift of Dr.s Ling-Mei Wang and Jacalyn Pierce, NCI, NIH), anti-GRB2 (Santa Cruz, CA), or anti-p85 (Upstate Biotechnologies, Lake Placid, NY). The precipitates were washed in lysis buffer and solubilized in SDS sample buffer. The samples were separated on $7.5 \%$ SDS-polyacrylamide gels before transfer to a PVDF membrane. The membranes were then probed with a monoclonal anti-phosphotyrosine antibody, RC20-H (Transduction Labs, Lexington, KY) to detect tyrosine phosphorylated IRS2 or with anti-IRS-2 antibody. The bound antibody was detected using enhanced chemiluminescence (Amersham, Arlington Heights, Illinois). Where indicated the blots were stripped and probed with control antibodies. Band intensities were analyzed using the public domain NIHImage software.

\section{Cellular proliferation assays}

For the study of cellular proliferation, the cells were incubated at $2.5 \times 10^{4}$ cells per well in a final volume of $0.2 \mathrm{ml}$ of complete RPMI in the presence or absence of muIL-4 $(10 \mathrm{ng} / \mathrm{ml})$, $\operatorname{LPS}(2 \mu \mathrm{g} / \mathrm{ml})$, or CD $40 \mathrm{~L}(1 \mu \mathrm{g} / \mathrm{ml})$ for $72 \mathrm{~h}$ at $37^{\circ} \mathrm{C}$. The wells were pulsed with $1 \mu \mathrm{Ci} /$ well ${ }^{3} \mathrm{H}$-thymidine for the final $4 \mathrm{~h}$ of culture before harvesting using a Packard harvestor and the Matrix 
9600 direct beta count system.

\section{RESULTS}

We previously showed that PI 3' kinase was involved in the anti-apoptotic activity of IL-4 on normal B-cells[22]. Several studies have suggested that STAT6 is not critical for the anti-apoptotic effects of IL-4 on T cells[29],[30]. To directly test the contribution of the STAT6 pathway on the regulation of resting B cell survival in response to IL-4, apoptosis studies were performed using B cells isolated from STAT6 null mice (Fig 1). Purified B cells derived from control or STAT6 null mice were cultured in the presence or absence of IL-4. In the absence of IL-4, B-cell viability steadily diminished over time dropping to $\sim 50 \%$ viability after $48 \mathrm{~h}$. However, in the presence of IL-4 B-cells from both control and STAT6 null mice remained $>80 \%$ viable after $60 \mathrm{~h}$ of culture (not shown). B cell apoptosis was directly analyzed by staining B220 ${ }^{+}$

Fig 1. Protection from apoptosis and proliferation induced by IL-4 in B cells from STAT6 null mice. A. Spleen cells isolated from control or STAT6 null mice were cultured in the presence or absence of mIL-4 (10 ng/ml) for $48 \mathrm{~h}$. The cells were then stained with FITC-conjugated anti-B220 antibody. After washing, the cells were ethanol-fixed and stained with propidium iodide. DNA content in B cells $\left(\mathrm{B} 220^{+}\right.$cells) was analyzed by FACScan and the percent hypodiploid is considered apoptotic. B. Resting splenic B cells were purified from control (open triangle) or STAT6 null mice (closed circle) and cultured with media alone, CD40L $(1 \mu \mathrm{g} / \mathrm{ml})$ in the presence of various concentrations of mIL-4 for $72 \mathrm{~h}$. $3 \mathrm{H}$-thymidine was added during the last $4 \mathrm{~h}$ of culture. Results are representative of two similar experiments. cells for DNA content using propidium iodide (Fig 1A). After $48 \mathrm{~h}$ of culture in the absence of IL-4, the $\mathrm{B}$ cell populations derived from control and STAT6 null mice demonstrated 56.6 and 59.8\% hypodiploid, apoptotic cells respectively. In the presence of IL-4 the levels of spontaneous apoptosis were reduced to 17.3 and $23.4 \%$. These results demonstrate that expression of STAT6 is not required for the IL-4-induced protection of resting splenic B cells from apoptosis.

Previous studies on STAT6 null B cells showed a diminished proliferative response to anti-IgM plus IL-4[31-33]. However, it has been reported
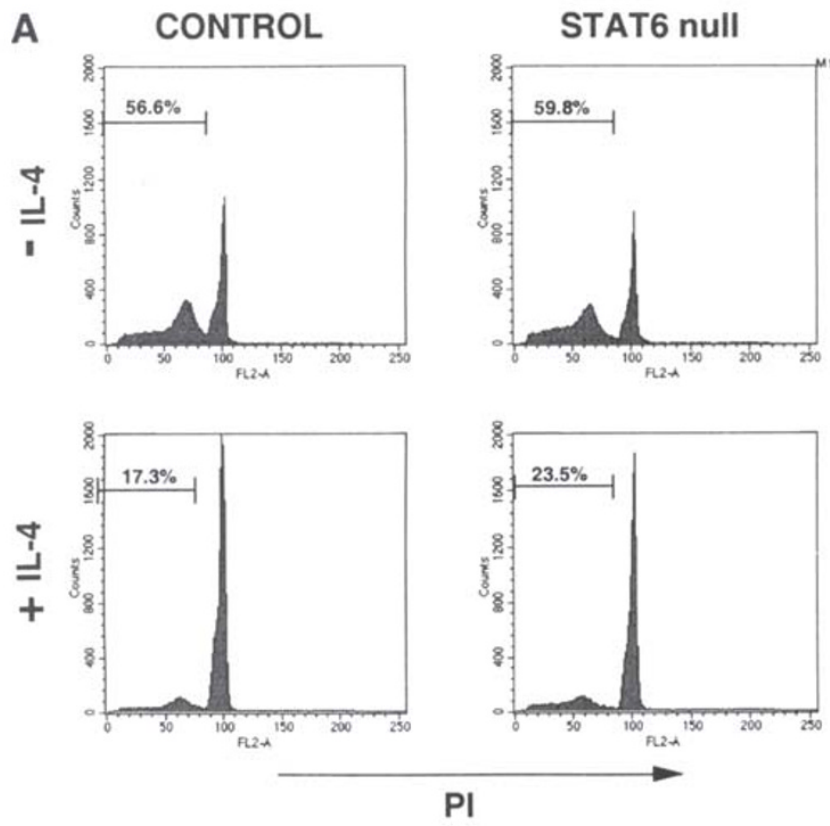
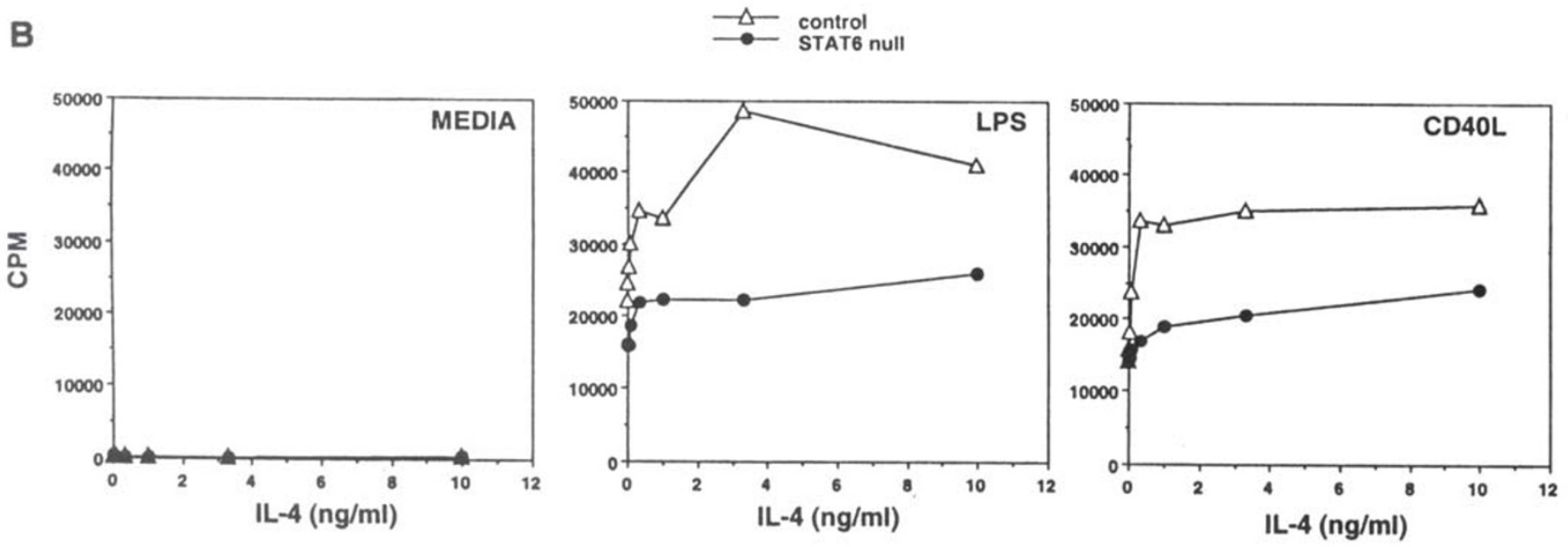
that anti-IgM itself can activate STAT6 in murine $\mathrm{B}$ cells[36]. To determine whether proliferation is diminished in response to other B -cell costimulants, we tested the responses to bacterial lipopolysaccharide (LPS) or the ligand for CD40 (CD40L). STAT6 null B cells showed a diminished, but detectable, proliferative response to LPS plus IL-4 and CD40L plus IL-4 when compared to control B cells (Fig 1B). B cells derived from STAT6 null mice were less sensitive to IL-4 and reached a plateau level of proliferation approximately half that of the control cells. These results indicate that STAT6 expression is not required for the IL-4-induced protection from apoptosis, but that it does contribute to a maximal proliferative response of B cells to IL- 4 in the presence of LPS or CD40L costimulation.

Since the polyclonal B cell activators LPS and CD40L have been shown to alter the IL-4 responsiveness of B cells[6],[37], we analyzed IL-4 signaling in resting and activated B cells. After IL-4 treatment, a tyrosine phosphorylated protein of 180 $\mathrm{kDa}$ (IRS2) was precipitated by anti-IRS2 and coprecipitated with antibodies to the p85 subunit of PI 3' kinase in both resting and activated splenic B cells (Fig 2A). Control blots with anti-IRS2 antibody confirm equal loading and that the $180 \mathrm{kDa}$ phosphoprotein associated with p85 is IRS2. This association was independent of STAT6 (Fig 2B). IRS2 protein was found to coprecipitate with the p85 subunit of PI 3' kinase in resting B cells isolated from control or STAT6 deficient mice only after IL-4 treatment. The same results were obtained using LPS blasts (data not shown). It was previously shown that interaction of $\mathrm{p} 85$ with IRS2 induces PI 3' kinase activity of the catalytic subunit[16]. We found that wortmannin blocked the IL-4-induced protection from apoptosis in LPS-activated B cells (data not shown), similar to the effects of wortmannin on the IL-4-mediated protection of resting cells[22]. These results are supported by the report by Fruman et al using LPS activated B cells derived from p85a deficient mice[26] and indicate a role for the IRS2/PI 3' kinase pathway in the IL-4-induced survival of activated B cells as well as the survival of resting B cells.

It has beens shown that IL-4 treatment will induce the association of GRB2 with phosphorylated IRS1 and 2 in IL-3-dependent cell lines[18],[19]. However, we found that phosphorylated IRS2 was not co-precipitated with anti-GRB2 in resting $B$ cells treated with IL-4 (Fig 3A) while it was with anti-p85. Interestingly, if the cells had been activated with LPS or CD40L, phosphorylated IRS2 was coprecipitated by both anti-p85 and anti-GRB2. In addition, IRS2 was coprecipitated with GRB2 in murine B lymphoma cell lines (data not shown). The signal intensity of tyrosine phosphorylated IRS2 coprecipitating with anti-GRB2 was approximately $0 \%, 80 \%$ and $70 \%$ of the signal for that coprecipitating with anti-p85 for resting, LPS-blast, and CD40L-blast B cells respectively. A similar pattern of coprecipitation was observed in resting and activated B cells isolated from STAT6 deficient mice (Fig 3B). IRS2 protein was found to coprecipitate with GRB2 in activated cells, but not resting cells, isolated from control or STAT6 defi-

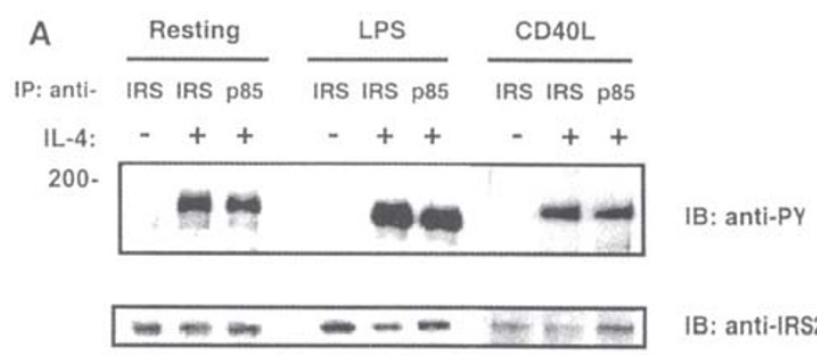

B

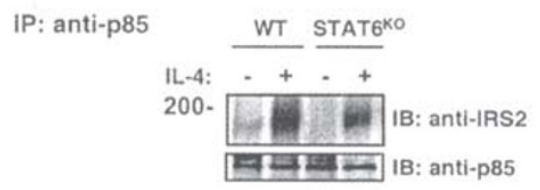

Fig 2. Coprecipitation of IRS2 with PI 3' kinase in wild type and STAT6 deficient B cells. A. Resting splenic B cells or B cells stimulated with LPS or CD40L for 48 hours were prepared as described in the Materials and Methods. The cells were treated with $\mathrm{mIL}-4(10 \mathrm{ng} / \mathrm{ml})$ for $10 \mathrm{~min}$ as indicated. The lysates were precipitated with anti-IRS2 or anti-p85 (p85) as indicated. Western blots were probed with anti-PY to detect tyrosine phosphorylated IRS2. Samples from resting and LPS-activated B-cells were run on the same gel, while the samples from CD40L-activated B-cells were run on a second gel. Blots were stripped and reprobed with anti-IRS2. These results are representative of over 5 separate experiments. B. Resting B cells isolated from WT or STAT6 deficient mice were incubated in the presence or absence of mIL-4 (10 ng/ml) as indicated. The lysates were precipitated with anti-p85. Western blots were probed with anti-IRS2. The blot was stripped and reprobed with antip85 as control. Results are representative of three similar experiments. 
cient mice, only after IL-4 treatment. These results suggest that B cell co-stimulation alters the IL-4activated IRS2 signalling pathway in a STAT6 independent manner such that phosphorylated IRS2 interacts with p85 and GRB2.

Activation of $B$ cells results in a general increase in protein synthesis; in our system LPS treatment for $48 \mathrm{~h}$ induced a 4-5-fold increase in the amount of total protein isolated from the same number of $B$ cells. Both resting and activated B cells express GRB2 protein (Fig 4) with LPS-blasts expressing $\sim 4$ fold more GRB2 on a per cell basis than resting B cells. The level of IRS2 protein expression is generally low and was not greatly changed by LPS stimulation (also seen in Fig 2). Therefore, the inability of IL-4 to induce the association of IRS2 with GRB2 in resting cells cannot be simply explained by a lack of protein expression.

While IL-4 treatment alone suppresses apoptosis

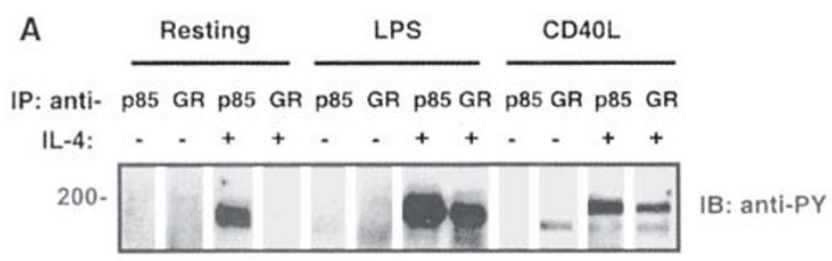

B

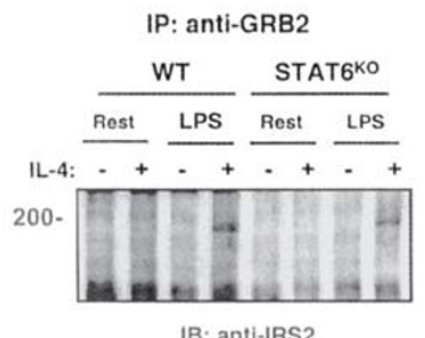

Fig 3. Coprecipitation of IRS2 with GRB2 in wild type and STAT6 deficient B cells. Resting splenic B cells or B cells stimulated with LPS or CD40L for $48 \mathrm{~h}$ were prepared as described in the Materials and Methods. The cells were treated with $\mathrm{mIL}-4(10 \mathrm{ng} / \mathrm{ml})$ for $10 \mathrm{~min}$ as indicated. The lysates were precipitated with anti-p85 (p85) or anti GRB2 (GR). Western blots were probed with anti-PY to detect tyrosine phosphorylated IRS2. These results are representative of over 5 separate experiments. B. Resting B cells and LPS-blasts prepared from WT or STAT6 deficient mice were treated with mIL- 4 as above. The lysates were precipitated with anti-GRB2. Western blots were probed with anti-IRS2. The large amount of light chain from the rabbit anti-GRB2 antibody used to immunoprecipitate and the low percentage of acrylamide used for the SDS-PAGE analysis of IRS2 precluded visualization of GRB2 levels on this blot. Results are representative of three similar experiments. of primary resting B cells through a PI 3' kinasedependent mechanism, it does not induce proliferation without a costimulus[6]. We have shown that one outcome of stimulation with LPS or CD40L is to enable the IL-4-induced association of IRS2 with GRB2. While it has been shown that IL-4 itself generally does not activate the Ras/Raf/MAPK pathway, there are recent studies showing that IL4 can augment proliferative responses downstream of this pathway stimulated by other factors in 32D cells[21]. Since the GRB2 adaptor can regulate the RasRaf/MAPK pathway, we examined the contribution of the MAPK pathway in the IL-4-induced costimulation of B-cell proliferation using an inhibitor of mitogen activated protein kinase kinase (MEK1) which is upstream of ERK (Fig 5). The MEK1 inhibitor, PD98059, suppressed the IL-4induced $3 \mathrm{H}$-thymidine uptake of LPS treated B cells in a dose dependent manner with an IC50 of $\sim 20 \mathrm{mM}$ (using the LPS alone response as baseline). The inhibitor of JNK kinase, SB203580, had no effect on B cell proliferation (data not shown). Concentrations of PD98059 that suppressed the IL-4-induced proliferative response had no effect on the level of proliferation observed in response to LPS alone. An inhibitor of PI 3'-kinase, LY294002, had suppressive activity on B-cell proliferation in response to LPS alone and to LPS plus

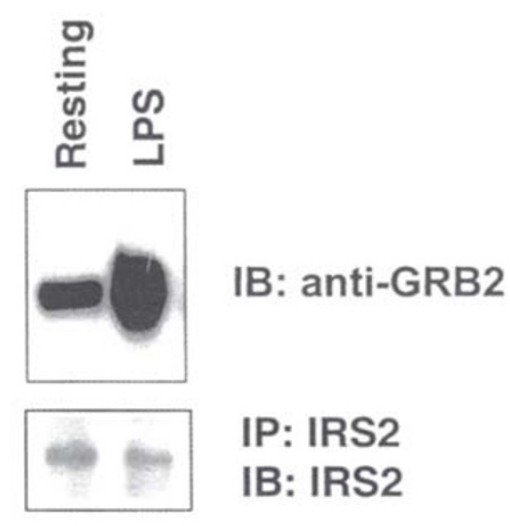

Fig 4. Resting B cells express GRB2 and IRS2. Top. Cell lysates prepared from $10^{6}$ resting $\mathrm{B}$ cells, equivalent to $\sim 5$ mg protein or $10^{6} \mathrm{LPS}$ blasts equivalent to $\sim 20 \mu \mathrm{g}$ protein were separated by SDS-PAGE. Western blots were probed with anti-GRB2. The region of the blot between the 33 and $20 \mathrm{kDa}$ molecular weight marker is shown. Bottom. Cell lysates were prepared from $10^{7}$ resting or LPS blasts and immunoprecipitated with anti-IRS2. Western blots were probed with anti-IRS2. The region of the blot between the 200 and $100 \mathrm{kDa}$ molecular weight marker is shown. These results are representative of 3 similar experiments. 


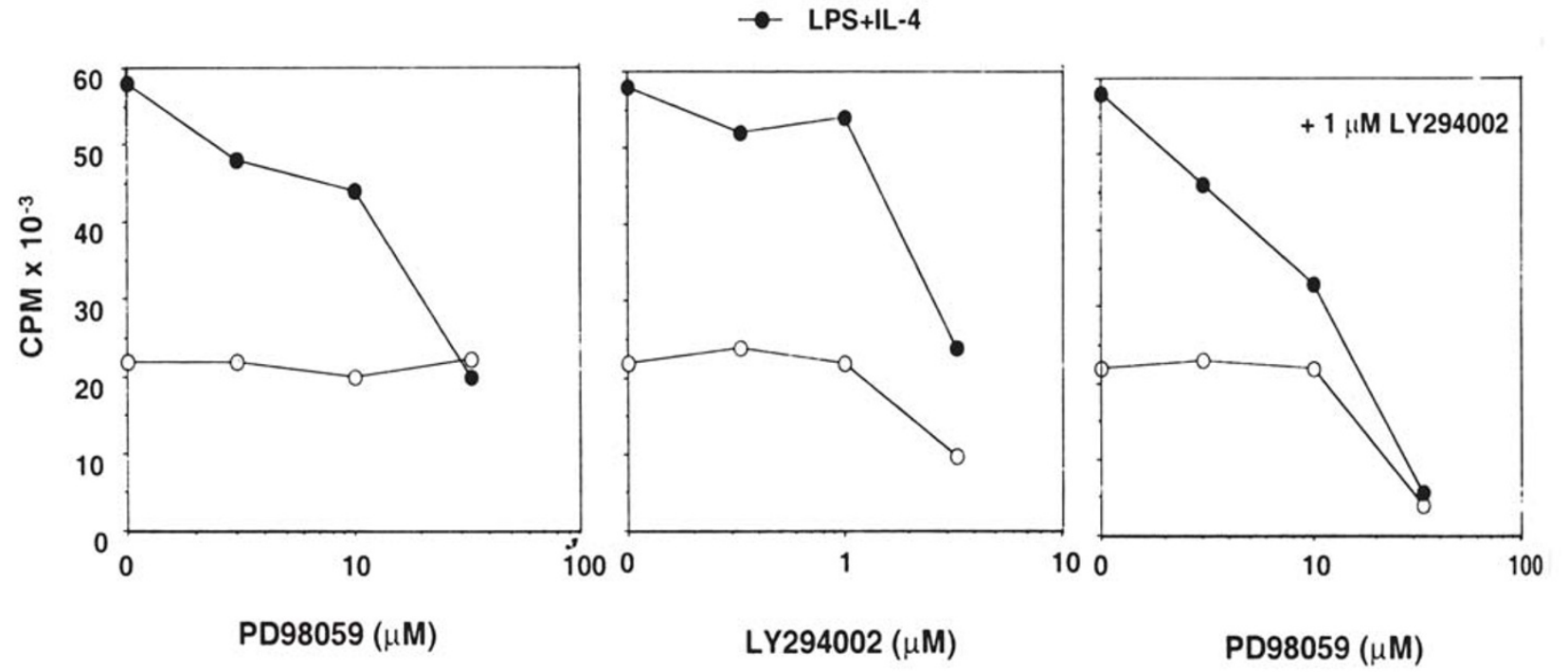

Fig 5. Effect of inhibitors of the PI 3' kinase and MAPK pathways on B-cell proliferation in response to LPS plus IL-4. Resting splenic B cells were purified and cultured with LPS ( $3 \mu \mathrm{g} / \mathrm{ml})$, open circles, or LPS plus IL-4 ( $5 \mathrm{ng} / \mathrm{ml})$, closed circles, in the presence or absence of various concentrations of PD98059 or LY294002 in triplicate as indicated for $72 \mathrm{~h}$. 3H-thymidine was added during the last $4 \mathrm{~h}$ of culture. The results are representative of 3 similar experiments.

IL-4 at $3 \mathrm{mM}$. Addition of a low concentation of LY294002 $(1 \mu \mathrm{M})$ to B cell cultures resulted in greater sensitivity to PD98059. In the presence of LY294002, the IC50 of PD98059 was $~ 3 \mu \mathrm{M}$ compared to $20 \mu \mathrm{M}$ in its absence. These results demonstrate that both the PI 3' kinase and MAP kinase pathways contribute to the IL-4-induced proliferation of activated B cells.

\section{DISCUSSION}

The development and maintenance of an immune response is achieved by regulated processes that include cell proliferation, differentiation, and programmed cell death via apoptosis. IL-4 has been shown to regulate all three of these processes in $\mathrm{B}$ and T lymphocytes. In this study, we analyzed the role of the insulin receptor substrate-2 and STAT6 in regulating the survival and proliferation of resting and activated B lymphocytes in response to IL4 treatment.

Firm support for a role of IRS family members in signaling the IL-4-induced proliferation has been obtained using the IL-3 dependent myeloid cell type 32D[18],[19]. We have shown that they are also important for signaling the prevention of apoptosis in response to IL-4[22]. Expression of the cDNA encoding IRS1 or IRS2 in $32 \mathrm{D}$ cells (32D-IRS) allows for a mitogenic response to IL-4.
In these transfected cells, IL-4 readily induces the tyrosine phosphorylation of IRS and its association with both p85 and GRB2. IL-3 withdrawal induces G1-arrest in 32D cells and subsequent death by apoptosis. We have previously shown that overexpression of IRS 1 protects $32 \mathrm{D}$ cells from death induced by IL-3 deprivation[22]. Although IL-4 was able to protect 32D cells from apoptosis in the absence of IRS1, the protection from apoptosis of cells cultured in IL-4 was greater in the presence of IRS1 and it reached levels comparable to those of cells cultured in IL-3. The IRS1dependent prevention of apoptosis was associated with the activation of PI 3 ' $\mathrm{K}$ since wortmannin and LY294002, two inhibitors of PI 3' kinase[23], [24], partially inhibited the prevention of apoptosis mediated by IL-4 in 32D-IRS1 cells after IL-3withdrawal, but not in $32 \mathrm{D}$ cells lacking IRS1 expression.

The activation of PI 3' kinase has been implicated in the protection from apoptosis mediated by other survival factors[38],[39], and it has been shown that insulin and IGF-1, which also use the IRS pathway, prevent apoptosis by a mechanism that requires PI 3' kinase[39],[40]. We observed a similar role for the IRS/PI 3' kinase pathway in the IL-4-induced protection from apoptosis in normal B cell. B cell express relatively low levels of 
IRS2. protein[22],[23]. However, IL-4 treatment induces the easily detectable tyrosine phosphorylation of IRS2. We observed the association of p85 with IRS2 after IL-4 stimulation of small resting B cells and activated B cells. In keeping with this observation, the inhibition pattern observed in B cells was quite similar to that seen in $32 \mathrm{D}$ cells. Wortmannin partially inhibited the protection from apoptosis by IL-4 in both resting[22] and LPS-activated B cells with an inhibitory concentration (IC50 $80 \mathrm{nM}$ ) consistant with its published affects on PI 3' kinase in cells[38],[41-43]. Similar results were obtained with LY294002, a competitive inhibitor of PI 3' kinase [22 and data not shown]. These results are consistant with studies of B cells lacking $\mathrm{p} 85 \mathrm{a}$ expression. In the absence of $\mathrm{p} 85 \mathrm{a}$, IL-4 was not able to protect B cells from apoptosis [26].

Relatively little is known about the mechanisms that transmit signals beyond PI 3' kinase in lymphocytes. Potential candidates include PKB/ Akt, p70S6 kinase, $\mathrm{PKC} \varepsilon$ and $\mathrm{PKC} \eta$ [44]. Although it has been demonstrated in several cell types that PI 3' kinase activation leads to the activation of p70S6K[39-41], we found that rapamycin does not block the protection from apoptosis by IL-4 in splenic B cells [22 and data not shown], suggesting that p70S6K is not leading to anti-apoptotic signals in this system. It is possible that the PI 3' kinase pathway leading to the protection from apoptosis in B cells is linked to one of the other downstream effector molecules such as PKB. PKB activation by growth factors induces the serine phosphorylation of Bad thereby diminishing its proapoptotic activity[45], however, it has been shown that IL-4 is not one of the growth factors with potent Bad-phosphorylating activity[46]. It remains to be determined whether IL-4 treatment of splenic $B$ cells induces $\mathrm{PKB}$-dependent post-translational modification of other signaling molecules that function to prevent apoptosis.

Strikingly, we observed that activation of B cells by LPS or CD40L altered the IL-4-stimulated IRS2 pathway such that IRS2 and GRB2 were found to associate. Similar studies using anti-IgM activated B cells were hampered by the extensive levels of B cell apoptosis induced by this treatment[7, 8, 47 and $\mathrm{ADK}$ personal observations]. It has been shown previously that B cell activation enhances expression of the IL-4 receptor by 2-fold[11]. However, B-cell activation by CD40L also alters the kinetics of association of JAK3 with the tyrosine phosphatase SHP-2[48]. This was accomplished without affecting the composition of the IL-4 receptor complex[48], making it unlikely that the change in IL-4 signaling after activation is simply due to an increase in receptor number. Although we clearly see potent tyrosine phosphorylation of IRS2 in response to IL-4 treatment of resting B cells, it was not found associated with GRB2. One possible explanation is that LPS-activation may alter the ratio of these two signaling molecules as well as the specific activity of tyrosine phosphorylation of IRS2. In addition, the inability of IL-4 to induce the formation of IRS2/GRB2 complexes in resting B cells may involve the differential activation and recruitment of specific phosphatases, kinases, or other adaptor proteins to IRS2 itself or to other components of the IL-4 receptor complex. A corollary to this possibility is that the single GRB2-binding site in IRS2 may not be a target for tyrosine phosphorylation in resting cells while it is in activated cells. We have assayed for the association of SHP2 with IRS2 in B lymphocytes but have not been able to detect any coprecipitation of SHP2 with IRS2 in either resting or activated $\mathrm{B}$ cells (ADK, personal observations).

Interestingly, IL-4 protects B cells isolated from STAT6 null mice from spontaneous apoptosis. Furthermore, IL-4 was able to stimulate IRS2 phosphorylation and its association with p85 in these cell populations. This suggests the possibility that STAT6-regulated gene expression is not involved in the protection from apoptosis mediated by IL-4. Consistant with our results in B cells, studies in $\mathrm{T}$ cells derived from STAT6 null mice found that they survive normally in vitro in the presence of IL-4 [29],[30].

Although the lack of STAT6 expression had no effect on the ability of IL-4 to protect B cells from apoptosis, it clearly affected the proliferative response to IL-4-. The mechanism by which STAT6 might regulate the ability of IL-4 to costimulate cell cycle in B cells is unclear. Kaplan et al have found that the proliferative defect observed in $\mathrm{T}$ cells derived from STAT6 deficient mice is associated 
with the failure to down-modulate $\mathrm{p}^{27 \text { Kip-1 }}[30]$. While LPS treatment downmodulates p2 $7^{k i p} 1$ expression in resting $B$ cells, we have not seen an additional effect of IL-4 on this cyclin-dependent kinase inhibitor (data not shown). We have shown that in the absence of STAT6 expression, IL-4 is able to induce the tyrosine phosphorylation of IRS2, its association with PI 3' kinase in resting cells and its association with both PI 3' kinase and GRB2 in activated cells. These results indicate that STAT6 is not regulating $\mathrm{B}$ cell proliferation at the level of early events in the IRS2 signaling pathway. Signaling studies in $32 \mathrm{D}$ cells indicate that the ability of IL-4 to induce c-myc is related to IRS1 activation and separable from its ability to activate STAT6 [27] and IL-4 is able to induce c-myc expression in B cells derived from STAT6 deficient mice (ADK, personal observation). Further analyses will be required to determine the role of STAT6 in regulating the IL- 4- induced proliferation of splenic B cells.

The involvement of the MAPK pathway in IL-4 signaling is controversial. Most analyses have found that IL-4 itself does not activate Ras, Raf, or induce phosphorylation of ERK1 and 2, although there are a few exceptions[11],[49]. However, a recent study found that IL-4 signaling could enhance proliferation of $32 \mathrm{D}$ cells in response to IGF1 through the MAP kinase pathway[21]. One can envision a scenario whereby a B cell stimulant such as LPS activates the MAP kinase pathway and that IL-4, via signaling IRS2/GRB2/SOS, either enhances this pathway or leads to a downstream effector whose function is dependent upon this pathway to mediate a proliferative response. In either case, inhibition of the MAPK pathway with agents such as PD98059 will suppress the IL-4-mediated proliferation. At this time we favor the latter possibility since IL-4 did not induce or enhance the level of phospho-ERK detected in lysates derived from resting or LPS-activated B cells (data not shown). While the ability of IL-4 to stimulate the tyrosine phosphorylation of SHC is weak to nil[11],[21],[49], we cannot yet completely rule out the possibility that the SHC/GRB2/Ras/Raf/MAPK pathway participates in the IL-4-induced proliferation of B cells.

Clearly the regulation of normal B cell proliferation in response to IL-4 is complex and requires modifications in cell signaling proteins induced by another B-cell activating agent. Two modifications with such activity have thus far been described, the association of JAK3 with SHP-2[48] and the association of IRS2 with GRB2 [herein]. Future analyses will be required to test whether these specific biochemical changes are directly responsible for the IL-4-induced proliferation of activated B cells.

\section{ACKNOWLEDGMENTS}

We acknowledge Dr. Jacalyn Pierce for IRS2 specific reagents, Dr. Marilyn Kehry for the CD40L preparation, and Dr. William E. Paul for providing STAT6 null mice and critical reading of the manuscript. In addition we acknowledge Dr. David Scott for helpful suggestions. This work supported REFAnerieanged Cross and by PHS CA77415, and AI38985.

[1] Cohen JJ, Duke RC. Apoptosis and programmed cell death in immunity Ann Rev Immunol 1992; 10:267-84.

[2] Scott DW, Grdina T, Shi Y. T cells commit suicide, but B cells are murdered! J Immunol 1996; 156:2352-6.

[3] Paul WE. Interleukin-4: a prototypic immunoregulatory lymphokine. Blood 1991; 77:1859-65.

[4] Oliver K, Noelle RJ, Uhr JW, Krammer PH, Vitetta ES. B-cell growth factor (B-cell growth factor I or B-cellstimulating factor, provisional 1) is a differentiation factor for resting B cells and may not induce cell growth. Proc Natl Acad Sci USA 1985; 82:2465-7.

[5] Rabin EM, OHara J, Paul WE. B cell stimulatory factor 1 activates resting B cells. Proc Natl Acad Sci USA 1985; 82:2935-9.

[6] Paul WE, Brown M, Hornbeck P, Mizuguchi J, Ohara J, Rabin E, Snapper C, Tsang W. Regulation of B-lymphocyte activation, proliferation, and differentiation. Ann NY Acad Sci 1987; 505:82-9.

[7] Ales-Martinez JE, Cuenda E, Gaur A, Scott DW. Prevention of B cell clonal deletion and anergy by activated T cells and their lymphokines. Sem in Immunol 1992; 4: 195-205.

[8] Parry SL, Hasbold J, Holman M, Klaus GGB. Hypercrosslinking surface IgM or IgD receptors on mature B cells induces apoptosis that is reversed by costimulation with IL-4 and anti-CD40. J Immunol 1994; 152:2821-9.

[9] Phillips NE, Gravel KA, Tumas K, Parker DC. IL-4 (B cell stimulatory factor 1) overcomes Fcg receptor-mediated inhibition of mouse B lymphocyte proliferation without affecting inhibition of c-myc mRNA induction. J Immunol 1988; 141:4243-9.

[10] Foote LC, Howard RG, Marshak-Rothstein A, Rothstein TL. IL-4 induces Fas resistance in B cells. J Immunol 1996; 157:2749-53.

[11] Nelms K, Keegan AD, Zamorano J, Ryan JJ, Paul WE. The IL-4 Receptor: signaling mechanisms and biologic 
functions. Annual Reviews in Immunol 1999; 17:70138.

[12] Callard RE, Matthews DJ, Hibbert L. IL-4 and IL-13 receptors: are they one and the same? Immunol Today 1996; 17:108-10.

[13] Yin T, Tsang M, Yang Y-C. JAK1 kinase forms complexes with interleukin-4 receptor and 4PS/IRS-1 protein and is activated by IL-4 and IL-9 in T lymphocytes. J Biol Chem 1994; 269:26614-7.

[14] Miyazaki T, Kawahara A, Fujii H, Nakagawa Y, Minami Y, Lui Z-J, Oishi I, Silvennoinen O, Witthuhn BA, Ihle JN, Taniguchi T. Functional activation of Jak1 and Jak3 by selective association with IL-2 receptor subunits. Science 1994; 266:1045-7.

[15] Russell SM, Johnston JA, Noguchi M, Kawamura M, Bacon CM, Friedmann M, Berg M. et al. Interaction of IL-2Rb and gc chains with Jak1 and Jak3: Implications for XSCID and XCID. Science 1994; 266:1042-5.

[16] Wang L-M, Keegan AD, Paul WE, Heidaran MA, Gutkind JS, Pierce JH. IL-4 activates a distinct signal transduction cascade from IL-3 in factor-dependent myeloid cells. EMBO J 1992; 11:4899-908.

[17] White MF, Kahn CR. The insulin signaling system. J Biol Chem 1994; 269:1-4.

[18] Sun XJ, Wang L-M, Zhang Y, Yenush L, Myers Jr MG, Glasheen E, Lane WS, Pierce JH, White MF. Role of IRS-2 in insulin and cytokine signaling. Nature 1995; 377:173-7.

[19] Wang L-M, Myers Jr MG, Sun X-J, Aaronson SA, White MF, Pierce JH. IRS-1: Essential for insulin- and IL-4stimulated mitogenesis in hematopoietic cells. Science 1993; 261:1591-94.

[20] Wang HY, Paul WE, Keegan AD. IL-4 function can be transferred to the IL-2 receptor by tyrosine containing sequences found in the IL-4 receptor-alpha chain. Immunity $1996 ;$ 4:113-21.

[21] Soon L, Flechner L, Gutkind JS, Wang LH, Baserga R, Pierce JH, Li W. Insulin-like growth factor I synergizes with interleukin 4 for hematopoietic cell proliferation independent of insulin receptor substrate expression. Mol Cell Biol 1999; 19:3816-28.

[22] Zamorano J, Wang HY, Wang L-M, Pierce JH, Keegan AD. IL-4 protects cells from apoptosis via the insulin receptor substrate pathway and a second independent signaling pathway. J Immunol 1996; 157:4926-34.

[23] Powis G, Bonjouklian R, Berggren MM, Gallegos A, Abraham R, Ashendel C, Zalkow L, Matter WF, Dodge J, Grindley G. Wortmannin, a potent and selective inhibitor of phosphatidylinositol-3-kinase. Cancer Res 1994; 54:2419-23.,p> [24] Vlahos CJ, Matter WF, Hui KY, Brown RF. A specific inhibitor of phosphatidylinositol 3-kinase, 2-(4-Morpholinyl)-8-phenyl-4H-1 benzopyran4-one (LY294002). J Biol Chem 1994; 269:5241-8.

[25] Welham MJ H, Bone H, M Levings M, et al. Insulin receptor substrate- 2 is the major $170-\mathrm{kDa}$ protein phosphorylated on tyrosine in response to cytokines in murine lymphohemopoietic cells. J Biol Chem 1997; 272: 1377-81.
[26] Fruman DA, Snapper SB, Yballe CM, Davidson L, Yu JY, Alt FW, Cantley LC. Impaired B cell development and proliferation in absence of phosphoinositide 3-kinase p85?. 1999; Science. 283:393-7.

[27] Pernis A, Witthuhn B, Keegan AD, Nelms K, Garfein E, Ihle JN, Paul WE, Pierce JH, Rothman P. Interleukin-4 signals through two related pathways. Proc Natl Acad Sci 1995; 92:7971-5.

[28] Wang HY, Zamorano J, Yoerkie J, Paul WE, Keegan AD. IL-4-induced tyrosine phosphorylation of IRS is dependent upon expression of JAK-1 in human fibrosarcoma cells. J Immunol 1997; 158:1037-40.

[29] Vella A, Teague TK, Ihle JN, Kappler J, Marrack P. IL4 or IL-7 prevents the death of resting T cells: STAT6 is probably not required for the effect of IL-4. J Exp Med 1997; 186:325-30.

[30] Kaplan MH, Daniel C, Schindler U, Grusby MJ. Stat proteins control lymphocyte proliferation by regulating p27Kip1 expression. Mol Cell Biol 1998; 18:1996-2003.

[31] Kaplan MH, Schindler U, Smiley ST, Grusby MJ. Stat6 is required for mediating responss to IL-4 and for the development of Th2 cells. Immunity. 1996; 4:313-9.

[32] Takeda K, Tanaka T, Shi W, Matsumoto M, Minami M, Kashiwamura, S-I, Nakanishi K, Yoshida N, Kishimoto T, Akira S. 1996; Essential role of STAT6 in IL-4 signalling. Nature 1996; 380:627-9.

[33] Shimoda K, Deursen JV, Sangster MY, Sarawar SR, Carson RT, Tripp RA, Chu C, Quelle FW, Nosaka T, Vignali DAA, Doherty PC, Grosveld G, Paul WE, Ihle JN. Lack of IL-4-induced Th2 response and IgE class switching in mice with disrupted STAT6 gene. Nature 1996; 380:630-3.

[34] Illera VA, Perandones CE, Stunz LL, Mower Jr DA, Ashman RF. 1993. Apoptosis in splenic B lymphocytes. Regulation by protein kinase C and IL-4. J Immunol 1993; 151:2965-73.

[35] Keegan AD, Nelms K, White MF, Wang L-M, Pierce JH, Paul WE. An IL-4 receptor region containing an insulin receptor motif is important for IL-4 mediated IRS-1 phosphorylation and proliferation. Cell 1994; 76:81120.

[36] Karras JG, Wang Z, Coniglio SJ, Frank DA, Rothstein TL. Antigen receptor engagement in B cells induces nuclear expression of STAT5 and STAT6 protein that bind and transactivate an IFN activation site. J Immunol 1996; 157:39-47.

[37] Durie FH, Foy TM, Masters SR, Laman JD, Noelle RJ. The role of CD40 in the regulation of humoral and cellmediated immunity. Immunol Today 1994; 15:406-10.

[38] Yao R, GE Cooper GE. Requirement for phosphatidylinositol- 3 kinase in the prevention of apoptosis by nerve growth factor. Science 1995; 267: 2003-6.

[39] Minshall C, Arkins S, Freund GG, Kelley KW. Requirement for phosphatidylinositol 3' kinase to protect hemopoietic progenitors against apoptosis depends upon the extracellular survival factor. J Immunol 1996; 156: 939-47. 
[40] Myers MG, Grammar TC, Wang LM, Sun XJ, Pierce JH, Blenis J, White MF. Insulin receptor substrate-1 mediates phosphatidylinositol 3'-kinase and p70S6K signaling during insulin, insulin-like growth factor-1, and interleukin-4 stimulation. J Biol Chem 1994; 269:287839.

[41] Cheatham B, Vlahos CJ, Cheatham L, Wang L, Blenis J, Kahn CR. Phosphatidylinositol 3-kinase activation is required for insulin stimulation of pp70 S6 kinase, DNA synthesis, and glucose transporter translocation. Mol Cell Biol 1994; 14:4902-11.

[42] Ward SG, June CH, Olive D. PI 3-kinase: a pivotal pathway in T- cell activation? Immunol Today 1996; 17: 187-95.

[43] Weng Q-P, Andrabi K, Klippel A, Kozlowski MT, Williams LT, Avruch J. Phosphatidylinositol 3-kinase signals activation of p70 S6 kinase in situ through sitespecific p70 phosphorylation. Proc Natl Acad Sci USA 1995; 92:5744-8.

[44] Franke TF, Kaplan DR, Cantley LC. PI3K: Downstream AKTion blocks apoptosis. Cell 1997; 88:435-7.
[45] Datta SR, Dudek H, Tao Z, Masters S, Fu H, Gotoh Y, Greenberg ME. AKT phosphorylation of BAD couples survival signals to the cell-intrinsic death machinery. Cell 1997; 91:231-41.

[46] Hinton H J, Welham MJ. Cytokine-induced protein kinase $\mathrm{B}$ activation and Bad phosphorylation do not correlate with cell survival of hemopoietic cells. J Immunol 1999; 162:7002-9.

[47] Scott DW, Lamers M, Kohler G, Sidman CL, Maddox B, Carsetti R. Role of c-myc and CD45 in spontaneous and anti-receptor-induced apoptosis in adult murine B cells. Int Immunol 1996; 8:1375-85.

[48] Siepmann K, Wohelleben G, Gray D. CD40-mediated regulation of IL-4 signaling pathways in B lymphocytes. Eur J Immunol 1996; 26:1544-52. class switching in mice with disrupted STAT6 gene. Nature 1996; 380: 630-33.

[49] Keegan AD and Zamorano J. Signaling by the interleukin4 receptor: Contribution of multiple signalling pathway. Cell Research 1998; 8:1-13. 